\title{
LITERATURA, PSCICANÁLIE E PAPÉIS DE GÊNERO EM “THE STORY OF AN HOUR": UMA LEITURA DO CONTO DE KATE CHOPIN
}

Natalia Helena Wiechmann é doutoranda em Estudos Literários pela Unesp de Araraquara-SP e docente do Centro Universitário Unifafine, em Bebedouro-SP.

E-mail: nataliahw@hotmail.com

\section{Resumo}

Este artigo tem por objetivo analisar o conto "The Story of an Hour", da escritora norte-americana Kate Chopin (1850-1904), a partir da intersecção entre literatura, Psicanálise e questões de gênero. Para isso, nosso foco recairá sobre as estratégias narrativas do texto literário, tais quais as imagens e metáforas, o foco narrativo, a ambientação, os jogos de palavras, os personagens e outros recursos dos quais a narrativa se utilize que possam ser interpretados a partir da intersecção proposta. $\mathrm{O}$ conto analisado trata das frustrações de uma personagem feminina em conflito com a sociedade que a circunda e seu final altamente irônico lança questões sobre a (im)possibilidade de superação dos papéis de gênero veiculados pela sociedade patriarcal. Além disso, o texto de Kate Chopin deixa lacunas a serem preenchidas pelo interpretação do leitor, o que se comprova com a análise das metáforas, das imagens sensoriais e do tom de ironia, por exemplo, utilizados pela autora para criar no texto uma camada de significação subtextual em que operam, significativamente, a entrelinha e a ambigüidade construída pela sobreposição de sentidos.

\begin{abstract}
This paper aims at analyzing the short story "The Story of an Hour", written by the North-American author Kate Chopin (18501904), by intersecting literature, psychoanalysis and gender issues. In order to do that, we will focus on the narrative strategies of the literary text, such as imagery, metaphors, the narrator's perspective, the setting, word plays, characters and other resources of the narrative that can be interpreted through the proposed intersection. The short story under analysis deals with the frustrations of a female character in conflict with the society around her and its highly ironic ending throws up questions about the (im)possibility of overcoming the gender roles conveyed by the patriarchal society. Besides that, Kate Chopin's text leaves blank spaces to be filled by the reader's interpretation, which is proved with the analysis of the metaphors, the sensory images, and the irony, for example, all used by the author in order to create a subtextual layer of meaning in the text in which the act of reading between the lines and the ambiguity created by the superposition of meanings operate significantly for the understanding of the story.
\end{abstract}

\section{1) Introdução}

"The Story of an hour" foi publicado pela primeira vez em 1894 na revista Vogue sob o título de "The Dream of an hour". No ano seguinte, a autora modifica o título do conto para publicação no periódico St. Louis Life e, em 1897, inclui esse conto na coletânea intitulada A Night in Acadie.

Geralmente traduzido por "A história de uma hora", esse conto se tornou um dos mais famosos de Kate Chopin e trata do curto período na vida de sua protagonista, Louise Mallard, entre o momento em que ela recebe a notícia da morte de seu marido em um acidente ferroviário e o desfecho final, com a revelação de que tudo não passou de um engano. Nesse meio tempo, a protagonista refletira sobre como sua vida seria daquele momento em diante, sem o marido ao seu lado, o que a levou a vislumbrar a 
liberdade de que poderia gozar para o resto de seus dias. Porém, com o retorno de Mr. Mallard, a liberdade se esvai e, não suportando esse conflito, Mrs. Mallard morre.

Ainda que resumido a linhas gerais, percebe-se que o conto lida com expectativas frustradas e que o fato de se tratar de uma personagem feminina no centro de toda a ação e reflexão da história é nuclear para sua análise. De fato, a construção de personagens femininas em conflito com a sociedade que as circunda é recorrente em toda a obra de Kate Chopin. A mulher representada por essas personagens está inserida na sociedade patriarcal do século XIX e se coloca em busca de sua identidade, mas, ao mesmo tempo, encontra-se em constante conflito com a situação dominante.

Nesse sentido, o que chamamos de estratégias narrativas também pode ser pensado como estratégias discursivas, isto é, meios pelos quais, no discurso, deixam-se entrever convicções ideológicas com o objetivo de produzir determinados sentidos. Nesse caso, o ponto de vista do narrador, a construção das personagens, a delimitação de tempo e espaço, entre outros aspectos da narrativa devem ser tomados como mecanismos para a expressão de uma ideologia ao mesmo tempo em que se ligam à própria estrutura narrativa. Essa relação, conforme afirma Adorno (2003), torna-se indissociável para a obra de arte: "A referência ao social não deve levar para fora da obra de arte, mas sim levar mais fundo para dentro dela. [...] (p.66)." Dessa forma, compreendemos que as referências ao social devem ser consideradas a partir do texto literário: "[As emoções e experiências individuais] só se tornam artísticas quando, justamente em virtude da especificação que adquirem ao ganhar forma estética, conquistam sua participação no universal " (ADORNO, 2003, p.66).

É importante destacar que Kate Chopin, ao publicar suas histórias com protagonistas femininas em busca de emancipação, foi condenada pela crítica da época por abordar temas considerados polêmicos e imorais. O texto considerado sua obra prima, The Awakening, publicado em 1899, é o melhor exemplo da hostilidade na recepção crítica da época:

The "new woman" - demanding social, economic, and political equality - was already a common topic of public discussion and subject of fiction. But the depiction of such an unrepentant (if ultimately deeply psychologically confused) sensualist as Edna Pontellier was more than many of the critics of the time could allow to pass. The book was called "trite and sordid", "essentially vulgar", and unhealthily introspective and morbid in feeling". (FRANKLIN et. al., 2008, p.428)

Como resultado dessa recepção crítica, ainda hoje a autora é pouco conhecida na literatura mundial e foi com o trabalho da crítica literária feminista, em especial de vertente norte-americana, que sua obra passou a integrar os currículos acadêmicos de literatura. Por consequiência, os textos de Chopin tem sido resgatados e apreciados por trazerem temas que ainda são atuais, como a luta da mulher pelo reconhecimento de seu espaço, seja na atuação profissional, nas relações interpessoais e até mesmo na literatura.

Para a literatura norte-americana, a obra de Kate Chopin costuma ser classificada como realista. Isso se dá por suas narrativas seguirem um estilo conciso e 
que, ao mesmo tempo, privilegia as descrições dos ambientes com o objetivo de construir as personagens em seus aspectos emocionais e subjetivos. Por outro lado, seu texto vai deixando lacunas propositalmente para que o leitor as preencha, fazendo o trabalho de interpretação, e uma dessas lacunas é o freqüente tom irônico empregado para lidar com questões que envolvam a moral. No caso de "The Story of an Hour", essas questões dizem respeito aos papeis sociais convencionais de mulheres e homens, em especial no que se refere ao casamento e às conseqüentes restrições às quais as mulheres são submetidas em oposição à liberdade e à sexualidade. É nesse conflito, portanto, que o conto se centra e é a partir dele que o percurso narrativo suscita hipóteses interpretativas que tentaremos relacionar com a Psicanálise.

\section{2) A história de uma hora}

Como mencionamos anteriormente, o conto em análise nos apresenta um momento na vida de Louise Mallard em que a protagonista precisa lidar com a notícia da morte de seu marido, Brently Mallard, por ocasião de um acidente ferroviário. Seus amigos e familiares tomam os cuidados necessários na tentativa de minimizar a dor da protagonista, uma vez que ela sofria de problemas cardíacos e poderia, supunha-se, não agüentar a dor da perda. Ao receber a notícia, a reação inicial de Mrs. Mallard é o choro aflito nos braços da irmã, o que, em seguida, dá espaço para a necessidade de se isolar do mundo. Mrs. Mallard, então, dirige-se para seu quarto e, trancada a porta, passa a observar pela janela tudo o que acontece do lado de fora da casa. Seus pensamentos e sentimentos desencadeados pela trágica notícia se misturam às sensações que ela experimenta na contemplação da natureza exterior, fazendo crescer em si uma força que ela não consegue definir e contra a qual ela tenta lutar, mas que toma conta de seu ser completamente.

Quando se entrega a essa força, Louise Mallard pronuncia: "free, free, free!" (CHOPIN, 2011, p.80). Daí em diante a protagonista consegue entender o significado do que está sentindo e da morte de Mr. Mallard e imagina uma vida nova em que poderia viver apenas por si mesma. Em meio às reflexões, a viúva é chamada por sua irmã que se mostra preocupada com seu estado de saúde e é levada de volta à sala em que se encontram amigos e familiares. No mesmo momento, a porta da sala se abre e por ela adentra Mr. Mallard, que nem mesmo ouvira falar do acidente e que, com sua chegada, vê a esposa sofrer um ataque do coração e morrer. Com a chegada dos médicos, a causa da morte é sentenciada: "When the doctors came they said she had died of heart disease - of joy that kills" (CHOPIN, 2011, p.82).

Apesar de tratar de um breve momento na história de Louise Mallard, percebe-se que, na verdade, o conto sintetiza sua vida, dividindo-a em três momentos: a vida ao lado do marido, o vislumbrar de sua vida sem Mr. Mallard e o fim de sua própria vida com o retorno do marido. No entanto, a interligação entre esses três momentos e o significado de cada um deles são de conhecimento apenas do leitor, uma vez que é o narrador onisciente quem adentra a intimidade das reflexões da protagonista e que nos 
permite acompanhá-lo nesse percurso. É por isso, também, que ao final do conto o leitor se depara com um jogo de palavras que dá à história um final tragicamente irônico, pois a cumplicidade que se estabeleceu entre narrador e leitor nos faz ver a morte de Mrs. Mallard não como uma ocorrência motivada pela euforia de rever o marido, mas, sim, pela frustração de perder as perspectivas de futuro que a morte de Mr. Mallard lhe havia apresentado. Logo, é a perspectiva do narrador que nos permite entender completamente a protagonista, bem como é através de seu ponto de vista que a crítica a valores sociais poderá ser feita.

Comecemos, no entanto, a refletir sobre o conto a partir de suas informações iniciais: "Knowing that Mrs. Mallard was afflicted with a heart trouble, great care was taken to break to her as gently as possible the news of her husband's death" (CHOPIN, 2011, p. 79, grifos nossos). O que temos já no primeiro parágrafo da história é uma descrição da protagonista: uma mulher que sofre de problemas do coração e que, por sua fragilidade, necessita de cuidados diante da iminência de ser abalada por uma tragédia. Considerando a época em que o conto foi escrito e publicado, no final do século XIX, vemos que essa descrição é condizente com o ideal de feminilidade da sociedade patriarcal e sustentada por diversos pensadores, como Rousseau, para quem

[...] a fragilidade, a doçura, a submissão ao homem são atitudes cultivadas pela educação das moças para que elas, a partir dessa posição, constituam os machos de que precisam para formar família, criar os filhos, garantir a espécie. As mulheres devem ser educadas para se tornar recatadas e resistentes ao sexo de modo a sustentar, com seu negaceio, a virilidade dos parceiros; frágeis e desprotegidas para mobilizar neles a força, a potência, o desejo de proteção; submissas e modestas para melhor governar a casa e a família. (KEHL, 2008, p. 61, grifo da autora)

A representação da figura feminina, portanto, vai ao encontro dos preceitos patriarcais, incluindo-se a forma de referência à protagonista: Mrs. Mallard, isto é, a esposa de Brently Mallard. Dessa forma, a referência é feita ao estado civil de esposa, não à identidade da mulher, mas com a morte do marido a protagonista será chamada, então, por seu primeiro nome - Louise, marcando na narrativa a retomada de uma vida anterior ao casamento, a transformação da personagem e a quebra do laço que a aprisionava sob o título de esposa.

Contudo, fica visível que a morte e, por consequiência, as mudanças na vida de Mrs. Mallard se constituem apenas na palavra. Queremos dizer, com isso, que saltam aos olhos as expressões indicativas da morte por meio da fala sobre essa morte, e não numa visualização, de fato, de Brently Mallard morto. Em outras palavras, a morte não se instaura por eventos - tais como um funeral ou a presença de um cadáver, por exemplo - mas pela enunciação dessa morte através da escolha vocabular: "the news of her husband's death", "broken sentences", "veiled hints that revealed in half concealing", "intelligence of the railroad disaster was received", "Brently Mallard's name", "a second telegram" e "the sad message" compõem as frases que inscrevem a morte de Brently Mallard na vida de sua esposa. Com isso, o texto sugere, por um lado, 
que o discurso cria, faz existir o fato, mas, por outro lado, também abre espaço para questionarmos a credibilidade desse fato.

Após um primeiro choro convulsivo, a protagonista decide retirar-se para o quarto, sozinha, numa atitude comum a alguém que precisa entender e lidar com o processo do luto. Esse processo pode ser definido como:

\begin{abstract}
Via de regra, luto é a reação à perda de uma pessoa amada ou de uma abstração que ocupa seu lugar, como pátria, liberdade, um ideal etc. [...] Também é digno de nota que jamais nos ocorre ver o luto como um estado patológico e indicar tratamento médico para ele, embora ocasione um sério afastamento da conduta normal da vida. Confiamos em que será superado após certo tempo, e achamos que perturbá-lo é inapropriado, até mesmo prejudicial. (FREUD, 2010, p.128)
\end{abstract}

Nesse sentido, o narrador parece indicar que o comportamento de Mrs. Mallard não surpreende, apesar de antecipar que, de algum modo, a viúva se diferencia das outras mulheres: "She did not hear the story as many women have heard the same, with a paralyzed inability to accept its significance" (CHOPIN, 2011, p.79). A notícia inesperada funcionará, então, como uma cesura que vai separar o antes e o depois de Louise Mallard. Nesse sentido, podemos pensar que essa notícia é, ao mesmo tempo, um corte em sua história e uma ponte para o futuro:

Corte no sentido de apresentar [...] o surgimento de novas possibilidades e alternativas de vida. [...] Ponte porque essas novas perspectivas se oferecem para alguém que já conta com todo um percurso prévio e que, de todo modo, não conseguirá romper radicalmente com sua história.

[...]

Qualquer que seja a natureza dessa cesura, boa ou ruim, agradável ou dolorosa, o fato é que nossa reação sempre estará mesclada de componentes de transformação (as novas possibilidades para o futuro) e invariância (as novas possibilidades acontecem em determinada personalidade que já tem um passado). (CRUZ, 2011, p.224, grifos do autor)

Assim, o quarto é o local escolhido para o recolhimento, a introspecção e para tentar compreender as mudanças repentinas da vida isolando-se da esfera pública. Sua ambientação inclui uma poltrona grande e confortável, na qual a protagonista se abandona e passa a observar, pela janela à sua frente, o mundo exterior: "There stood, facing the open window, a comfortable, roomy armchair. Into this she sank, pressed down by a physiscal exhaustion that haunted her body and seemed to reach into her soul" (CHOPIN, 2011, p.79). Desse momento em diante, percebe-se que o narrador que se colocava entre a personagem e o leitor agora parece se fundir à protagonista, verbalizando e revelando ao leitor as sensações e os pensamentos de Mrs. Mallard que ela mesma não conseguira definir.

Pela janela, Mrs. Mallard vê "the tops of trees that were all aquiver with the new spring life" (CHOPIN, 2011, p.79) e sente "The delicious breath of rain" (CHOPIN, 2011, p.80), além de ouvir pardais gorjeando do telhado enquanto alguém cantava, 
distante, na rua e de poder admirar o céu azul entre as nuvens, como se fossem fragmentos de imagens, sons e sensações. Todas essas referências, na verdade, constituem metáforas que se associam diretamente à natureza e à liberdade e prenunciam a possibilidade de uma vida nova. Da mesma forma, a descrição detalhada do que se pode ver e ouvir pela janela sugere o novo olhar da protagonista, ou seja, uma nova percepção da vida e, por conseqüência, de si mesma.

Além de encontrarmos nessa descrição imagens sensoriais que metaforizam as novas perspectivas de Mrs. Mallard, vemos também que o narrador faz uso da metonímia para recriar o espaço externo: seu foco recai sobre as copas das árvores, o cheiro da chuva, as notas da canção e o beiral do telhado. Com isso, cria-se um sentido de contato com o espaço público, mas, ao mesmo tempo, mantém-se os limites entre a protagonista e o mundo externo. Esse limite é reafirmado pela presença concreta da janela, que fica entre o fechado e o aberto, interligando as duas instâncias ao passo que também as limita. Vista dessa forma, a janela pode ser entendida como uma metáfora que condensa em si a possibilidade de liberdade e libertação para Mrs. Mallard, contrapondo-se às amarras opressivas do espaço fechado.

O que chamamos de espaço fechado é, na verdade, a circunscrição do espaço reservado à mulher na sociedade patriarcal. Esse espaço se limita ao âmbito doméstico, privado, em que a mulher deve exercer exclusivamente os papéis sociais de esposa e mãe. Nesse sentido, as imagens e os sons que vem do espaço aberto, público, tornam-se símbolos da liberdade em oposição às restrições que a casa, o casamento, e a função social da mulher impõem.

Além disso, mais adiante no conto sabemos que o quarto do casal ficava em um andar superior da casa, o que sugere de antemão a ascensão da protagonista em direção à descoberta que ela vivenciará. O quarto fechado também se associa ao local onde as necessidades mais íntimas são reveladas ao mesmo tempo que escondidas e, por isso, numa perspectiva psicanalítica, pode representar o espaço onde se depositou tudo que foi escondido e reprimido. Será no quarto, portanto, que as frustrações da personagem e também as respostas para seus conflitos surgirão de modo consciente e será nesse local que acontecerá a manifestação do eu feminino.

A percepção do mundo externo suscita em Mrs. Mallard algo de inquietante e não familiar, como se os símbolos carregados pelos elementos da natureza externa transmutassem idéias em emoções. Do mesmo modo, sua descrição física também explicita essa mudança:

She was young, with a fair, calm face, whose lines bespoke repression and even a certain strength. But now there was a dull stare in her eyes, whose gaze was fixed away off yonder on one of those patches of blue sky. It was not a glance of reflection, but rather indicated a suspension of intelligent thought. (CHOPIN, 2011, p.80, grifos nossos)

Com a suspensão do raciocínio, Louise consegue vislumbrar uma mudança interna. A viúva sente, temerosa, algo acontecendo com ela, algo indefinível, que ela não consegue nomear e que vem dos sons, dos cheiros e da cor da natureza observada. 
Apesar de tentar repelir a força que vinha para possuí-la, seu corpo é dominado por ela e a mulher desiste de lutar. Nesse trecho não há fala da personagem, mas a fusão que se estabeleceu entre ela e o narrador nos permite conhecer sua interioridade. Ademais, a personagem não consegue verbalizar seu desejo, uma vez que isso seria assumi-lo como, de fato, um desejo, mas ela ainda está presa às amarras sociais e não pode fazêlo.

Quando desiste de lutar contra essa força, Louise pronuncia: "free, free, free!" (CHOPIN, 2011, p.80). Esse momento é como a revelação de um segredo, de um sentimento represado, que não podia ser dito, como tornar consciente e comunicável algo que antes a linguagem não dava conta de expressar - a necessidade de liberdade. Isso nos remete também à idéia de epifania, em que há a revelação súbita de algo até então oculto, mas que sempre esteve presente.

Percebemos, com isso, que a protagonista passa do silêncio, na contemplação das imagens sensoriais externas, à palavra, com a incorporação do sentimento de liberdade suscitado por essas imagens. Assim, ao pronunciar a liberdade, a protagonista supera quaisquer barreiras de resistência que encobriam a verdade do desejo: ela sempre soube o que significaria ser livre, mas apenas quando consegue pronunciar e materializar seu desejo na palavra é que ela passa a experimentar a liberdade.

Esse também é o único momento em que a protagonista assume a sua própria voz. O discurso indireto da narrativa muda para o discurso direto somente quando a protagonista consegue verbalizar seu estado de euforia em decorrência da liberdade recém-adquirida e é a partir desse momento que ela passa a ser chamada de Louise, seu primeiro nome, e não mais pelo nome de casada, o que concretiza a sua existência e afirmação enquanto indivíduo, não mais pelo papel social de esposa:

De certa forma esse despertar, essa tomada de conhecimento da feminilidade, é também o re-encontro de uma identidade que foi lançada ao esquecimento pela sociedade patriarcal, um re-encontro que é, agora, estranho ao ser que com ele se depara, pois este ser não se lembra mais o que foi um dia: restaram apenas traços, rastros que precisam ser religados, re-preenchidos e reinterpretados: a mulher/fênix retorna das cinzas que lhe foram imputadas por outrem como se de fato fossem suas e que ela descobriu, agora, não o serem. (ROSSI, 2007, p.3)

O trecho que segue a tomada de consciência de si e de sua liberdade enfatiza o prazer proporcionado pelo conflito inicial, um prazer corpóreo e sensual. Além disso, fica claro que a tomada de consciência de si enquanto indivíduo é inerente à consciência de sua sexualidade, antes reprimida provavelmente em detrimento do exercício da sexualidade do marido: "The vacant stare and the look of terror that had followed it went from her eyes. They stayed keen and bright. Her pulses beat fast, and the coursing blood warmed and relaxed every inch of her body" (CHOPIN, 2011, p.80).

A partir daí tem-se um entrecruzamento de enunciados que, por um lado, expressam a necessidade social do sofrimento pela perda do marido e, por outro, trazem as reflexões da protagonista sobre o sentido do casamento, sobre o amor que sentia pelo marido e sobre a liberdade pessoal: 
She knew that she would weep again when she saw the kind, tender hands folded in death; the face that had never looked save with love upon her, fixed and gray and dead. But she saw beyond that bitter moment a long procession of years to come that would belong to her absolutely. And she opened and spread her arms out to them in welcome.(CHOPIN, 2011, p.81)

O pensamento de Louise, agora livre de qualquer censura, ocupa os espaços da ação e ela reflete sobre os sacrifícios que fizera durante a vida de casada. Nessa reflexão, ressalta-se um tom irônico ao falar do amor que sentia por Mr. Mallard - "And yet she had loved him - sometimes. Often she had not. What did it matter!" (CHOPIN, 2011, p.81). Aqui, o uso dos advérbios de freqüência imprime o tom de ironia e desprezo em relação ao amor romântico e devotado convencionalmente atribuído à mulher: "Nosso pensamento segue o hábito da cultura que prescreve: casamento e amor devem andar juntos. Mas são conceitos completamente diferentes, dois rios que nascem em fontes opostas. Historicamente, casamento é uma coisa e amor é outra" (STRINGUINI, 2011, p263).

A atmosfera que se instaura nesse ponto da narrativa em muito se assemelha com a experiência do sonho. Nesse sentido, devemos nos lembrar do título original do conto, "The Dream of an hour", que tanto pode se referir ao sonho no sentido dos desejos e das expectativas para o futuro como também nos faz pensar em sonho enquanto a suspensão do raciocínio consciente para dar lugar ao devaneio, à manifestação dos desejos reprimidos e às lembranças revisitadas do passado.

Diante dos planos que Louise agora fazia, o que mais lhe agradava era reconhecer que não haveria mais ninguém para impor sua vontade sobre a dela. A vida de Louise irrompe, portanto, da morte do marido: "Free! Body and soul free!" (CHOPIN, 2011, p.81). Entende-se, com isso, que ao rever sua existência como mulher a personagem, no quarto, põe em xeque sua condição de passividade, ao mesmo tempo em que desempenha o papel esperado dela, isto é, o de uma viúva enclausurada no quarto para chorar a perda do marido. Isso fica marcado com a preocupação de sua irmã Josephine que, do lado de fora do quarto, implora para que Louise a deixe entrar, temendo por seu bem estar. Quando finalmente abre a porta, seu olhar era de triunfo e seu caminhar era de uma deusa da Vitória, quebrando o estereótipo convencional de viúva.

Abraçada à irmã, Louise desce as escadas em direção à sala novamente, ou seja, ela deixa o espaço em que tomou consciência de si, em que experimentou a liberdade, para retornar ao espaço do convívio social. Da mesma forma, a metáfora contida em subir as escadas para o quarto e depois descê-las sugere o retorno ao papel social de esposa e, agora, de viúva.

O conto, então, chega ao seu final com um desfecho altamente irônico e trágico: a porta da sala se abre e por ela entra Brently Mallard, que havia passado longe do acidente ferroviário. Louise, forçada a retornar ao seu papel de esposa, morre diante de todos, num ataque cardíaco chamado pelos médicos de "joy that kills" (CHOPIN, 2011, p.82). A ironia de relacionar a morte de Louise à euforia de reencontrar o marido 
permanece, no entanto, acessível apenas ao leitor, fazendo com que nos tornemos cúmplices de sua morte porque somente a nós é possível concluir sobre o real motivo de seu falecimento. Portanto, para o leitor fica nítido que a alegria e a esperança de Louise em um futuro de liberdade se transformam em decepção e desconsolo quando o engano da morte de Mr. Mallard se desfaz. Com isso, o desfecho do conto confirma a distância entre os anseios femininos e as convenções sociais do século XIX, uma vez que nos apresenta uma visão desesperançosa quanto à condição feminina e sua impotência diante da sociedade patriarcal.

Além disso, se retomamos o enredo à luz de seu final, percebemos que a protagonista é marcada desde o início pela falta de esperança, pois as informações iniciais a caracterizam como uma mulher frágil, portadora de doença do coração, seja essa doença física ou metafórica. Nesse contexto, o que é revelado é simultaneamente escondido, pois a morte de Mrs. Mallard por um ataque cardíaco é tão enganosa quanto a morte anunciada de Mr. Mallard.

Como tivemos acesso ao não-dito da personagem, sabemos que a alegria que a matou era na verdade a frustração de ver que tornar-se livre era impossível. Por isso podemos dizer que o despertar para a vida tornou-se a causa de sua morte e esse jogo irônico faz com que a narrativa se torne um grande chiste em que o despertar de Louise é abafado com o reaparecimento do marido.

Contudo, apesar de fisicamente aparecer apenas ao final do conto, a imagem do marido paira sobre toda a narrativa, como uma força opressora que regulamenta os pensamentos da esposa. Soma-se a isso o silêncio contínuo de Louise Mallard, cuja perspectiva é, na maior parte, transmitida ao leitor pela voz do narrador, o que reafirma a regra social de que o silêncio é um atributo das mulheres e, simultaneamente, uma força de contenção de suas vontades e anseios. Diante desse contexto histórico e social, a morte se torna o único meio de liberdade para Louise, ao passo que é vista pela sociedade patriarcal como punição.

É importante observar que para explicar a morte de Mrs. Mallard o narrador evoca novamente o ponto de vista masculino: "When the doctors came they said she had died of heart disease - of joy that kills" (CHOPIN, 2011, p.82). A voz que atesta a morte de Mrs. Mallard não contesta, porém, a credibilidade dessa morte por alegria em excesso, uma vez que "[...] essa é sem dúvida também a explicação que ao mesmo tempo consola o marido e satisfaz a sociedade" (THEOBALD, 2011, p.198).

\section{3) Considerações finais}

O conto analisado levanta inúmeras questões para as quais pudemos sugerir algumas respostas, mas que, sem dúvida, deixa diversas lacunas para que o leitor exerça a sua interpretação. Isso ocorre porque recursos utilizados por Chopin, tais quais as metáforas, as imagens sensoriais, o ponto de vista da narrativa e a ironia, por exemplo, criam no texto uma camada de significação subtextual em que operam a entrelinha e a ambigüidade construída pela sobreposição de sentidos. 
Sabemos que a ambigüidade e a multiplicidade de sentidos estão, na verdade, presentes em toda obra literária. O que se diferencia no conto de Chopin bem como em suas outras narrativas é o uso dessas características como meio de tratar de temas contrários à ideologia patriarcal do século XIX, como a necessidade de emancipação e de auto-afirmação da mulher e a busca por uma identidade feminina que não fosse construída pelo olhar opressivo do outro, mas sim pela consciência de si mesma e de seus desejos.

No entanto, não há, no conto, uma fala moralizante que regulamente as relações sociais. Em outras palavras, seu desfecho nos choca, mas mantém a história aberta para que o leitor preencha suas lacunas. Da mesma forma, não há sentimentalismos, apenas o tratamento delicado de um drama humano e, com isso, o conto nos leva a reconhecer a incrível capacidade que a vida também tem de surpreender a todo momento.

Nesse sentido, a morte se torna o fio condutor da narrativa: a morte noticiada à Mrs. Mallard é o que motiva a descoberta de si mesma e, por conseguinte, é o que gera sua própria morte, já prenunciada com a menção ao problema cardíaco de que sofria. De fato, ela via o mundo pelos olhos dos outros, vivia para os outros, e o reconhecimento de que teria que voltar a essa posição, isto é, de que a liberdade idealizada não seria mais concretizada é demais para Louise. O que temos, então, é uma história desde o início trágica e em direção à morte, pois para que continuasse a viver novamente no papel de Mrs. Mallard, a esposa, seria preciso matar Louise, a mulher. Viver como Louise, porém, não seria possível, uma vez que a realidade repressiva lhe frustraria os desejos. Ao final, temos, na verdade, duas mortes: para o âmbito social, é dada uma esposa que padece de felicidade por reencontrar o marido, mas para o leitor, único cúmplice da experiência libertadora de Louise, é dada uma morte que se transfigura em verdadeira liberdade.

Essa ironia do destino, como popularmente chamaríamos, recai também sobre a questão do luto, que é o momento de redirecionamento da energia vital para que se supere a perda de algo ou alguém querido. Louise faz isso: ao ser invadida por uma alegria imensa que a domina completamente, a protagonista vislumbra redirecionar sua energia para a própria liberdade, enfatizando-se as descrições ao redor dela que também mudam acompanhando esta ultrapassagem do luto pela perda do marido. No entanto, o mais irônico é descobrirmos, ao final, que o verdadeiro luto deverá acontecer com o retorno de Brently Mallard, pois a perda da possibilidade de viver a sua liberdade se torna insuportável.

Dessa forma, vemos que há uma ironia quanto ao próprio significado do luto, que já não é a tristeza pela morte do outro, mas, sim pela morte dela mesma, Louise, enquanto identidade feminina consciente de si e de seus desejos. A vida livre das restrições do casamento não acontece de fato, permanecendo apenas no discurso, o que sugere assim e desde o início, a impossibilidade de ser alcançada. 


\section{Referências}

ADORNO, Theodor W. Notas de Literatura I. Tradução e apresentação de Jorge de Almeida. São Paulo: Duas Cidades, 2003.

CHOPIN, Kate. The Story of an Hour. In: VIEGAS-FARIA, Beatriz; CARDOSO, Betina Mariante; BROSE, Elizabeth (Org.). Kate Chopin: contos traduzidos e comentados. Estudos literários e humanidades médicas. Porto Alegre: Casa Editorial Luminara, 2011.

CRUZ, Juarez Guedes. Meias de seda: o reencontro com o bom objeto.In: VIEGASFARIA, Beatriz; CARDOSO, Betina Mariante; BROSE, Elizabeth (Org.). Kate Chopin: contos traduzidos e comentados. Estudos literários e humanidades médicas. Porto Alegre: Casa Editorial Luminara, 2011.

FRANKLIN, Wayne; GURA, Philip; KLINKOWITZ, Jerome et. al. The Norton Anthology of American Literature: 1865 to the present. 7.ed. Vol.2. New York, London: Norton \& Company, 2008.

FREUD, Sigmund. Obras completas: Introdução ao Narcisismo, ensaios de Metapsicologia e outros textos - 1914-1916. Vol. 12. Tradução de Paulo César de Souza. São Paulo: Companhia das Letras, 2010.

KEHL, Maria Rita. Os homens constroem a feminilidade. In: Deslocamentos do Feminino. 2.ed. Rio de Janeiro: Imago, 2008.

ROSSI, Aparecido Donizete. Uma morte irônica: The Story of An Hour, de Kate Chopin. In: Anais do XII Seminário Nacional e III Seminário Internacional Mulher e Literatura: Gênero, Identidade e Hibridismo Cultural. Universidade Estadual de Santa Cruz: Ilhéus/Bahia, 2007. Disponível em: < http://www.uesc.br/seminariomulher/anais/PDF/APARECIDO\%20DONIZETE\%20RO

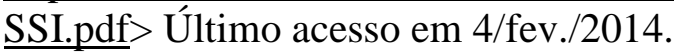

STRINGUINI, Vera. Amor e casamento em "Athénaise". In: VIEGAS-FARIA, Beatriz; CARDOSO, Betina Mariante; BROSE, Elizabeth (Org.). Kate Chopin: contos traduzidos e comentados. Estudos literários e humanidades médicas. Porto Alegre: Casa Editorial Luminara, 2011.

THEOBALD, Pedro. Uma hora de liberdade. In: VIEGAS-FARIA, Beatriz; CARDOSO, Betina Mariante; BROSE, Elizabeth (Org.). Kate Chopin: contos traduzidos e comentados. Estudos literários e humanidades médicas. Porto Alegre: Casa Editorial Luminara, 2011. 


\section{ANEXO \\ “The Story of an Hour" (1894) \\ by Kate Chopin}

Knowing that Mrs. Mallard was afflicted with a heart trouble, great care was taken to break to her as gently as possible the news of her husband's death. It was her sister Josephine who told her, in broken sentences; veiled hints that revealed in half concealing. Her husband's friend Richards was there, too, near her. It was he who had been in the newspaper office when intelligence of the railroad disaster was received, with Brently Mallard's name leading the list of "killed." He had only taken the time to assure himself of its truth by a second telegram, and had hastened to forestall any less careful, less tender friend in bearing the sad message.

She did not hear the story as many women have heard the same, with a paralyzed inability to accept its significance. She wept at once, with sudden, wild abandonment, in her sister's arms. When the storm of grief had spent itself she went away to her room alone. She would have no one follow her.

There stood, facing the open window, a comfortable, roomy armchair. Into this she sank, pressed down by a physical exhaustion that haunted her body and seemed to reach into her soul.

She could see in the open square before her house the tops of trees that were all aquiver with the new spring life. The delicious breath of rain was in the air. In the street below a peddler was crying his wares. The notes of a distant song which some one was singing reached her faintly, and countless sparrows were twittering in the eaves.

There were patches of blue sky showing here and there through the clouds that had met and piled one above the other in the west facing her window.

She sat with her head thrown back upon the cushion of the chair, quite motionless, except when a sob came up into her throat and shook her, as a child who has cried itself to sleep continues to sob in its dreams.

She was young, with a fair, calm face, whose lines bespoke repression and even a certain strength. But now there was a dull stare in her eyes, whose gaze was fixed away off yonder on one of those patches of blue sky. It was not a glance of reflection, but rather indicated a suspension of intelligent thought.

There was something coming to her and she was waiting for it, fearfully. What was it? She did not know; it was too subtle and elusive to name. But she felt it, creeping out of the sky, reaching toward her through the sounds, the scents, the color that filled the air.

Now her bosom rose and fell tumultuously. She was beginning to recognize this thing that was approaching to possess her, and she was striving to beat it back with her will--as powerless as her two white slender hands would have been. 
When she abandoned herself a little whispered word escaped her slightly parted lips. She said it over and over under her breath: "free, free, free!" The vacant stare and the look of terror that had followed it went from her eyes. They stayed keen and bright. Her pulses beat fast, and the coursing blood warmed and relaxed every inch of her body.

She did not stop to ask if it were or were not a monstrous joy that held her. A clear and exalted perception enabled her to dismiss the suggestion as trivial.

She knew that she would weep again when she saw the kind, tender hands folded in death; the face that had never looked save with love upon her, fixed and gray and dead. But she saw beyond that bitter moment a long procession of years to come that would belong to her absolutely. And she opened and spread her arms out to them in welcome.

There would be no one to live for during those coming years; she would live for herself. There would be no powerful will bending hers in that blind persistence with which men and women believe they have a right to impose a private will upon a fellowcreature. A kind intention or a cruel intention made the act seem no less a crime as she looked upon it in that brief moment of illumination.

And yet she had loved him--sometimes. Often she had not. What did it matter! What could love, the unsolved mystery, count for in face of this possession of selfassertion which she suddenly recognized as the strongest impulse of her being!

"Free! Body and soul free!" she kept whispering.

Josephine was kneeling before the closed door with her lips to the keyhole, imploring for admission. "Louise, open the door! I beg, open the door--you will make yourself ill. What are you doing Louise? For heaven's sake open the door."

"Go away. I am not making myself ill." No; she was drinking in a very elixir of life through that open window.

Her fancy was running riot along those days ahead of her. Spring days, and summer days, and all sorts of days that would be her own. She breathed a quick prayer that life might be long. It was only yesterday she had thought with a shudder that life might be long.

She arose at length and opened the door to her sister's importunities. There was a feverish triumph in her eyes, and she carried herself unwittingly like a goddess of Victory. She clasped her sister's waist, and together they descended the stairs. Richards stood waiting for them at the bottom.

Some one was opening the front door with a latchkey. It was Brently Mallard who entered, a little travel-stained, composedly carrying his grip-sack and umbrella. He had been far from the scene of accident, and did not even know there had been one. He stood amazed at Josephine's piercing cry; at Richards' quick motion to screen him from the view of his wife.

But Richards was too late.

When the doctors came they said she had died of heart disease-- of joy that kills. 
Disponível em:

<http://www.katechopin.org/pdfs/Kate\%20Chopin,\%20The\%20Story\%20of\%20an\%20 Hour.pdf>. Último acesso em 13/mar./2014. 